\title{
Special Issue Editorial: Functional Oxide Based Thin-Film Materials
}

\author{
Dong-Sing Wuu \\ Department of Materials Science and Engineering, National Chung Hsing University, 145 Xingda Road, \\ Taichung 40227, Taiwan; dsw@dragon.nchu.edu.tw
}

Received: 8 March 2020; Accepted: 10 March 2020; Published: 12 March 2020

Protective oxide coatings, such as $\mathrm{Al}_{2} \mathrm{O}_{3}$ and $\mathrm{Y}_{2} \mathrm{O}_{3}$ coatings, are widely used in semiconductor industries because of their hardness, high wear resistance, dielectric strength, high corrosion resistance, and chemical stability for plasma chambers [1]. Thin-film oxide barrier coatings with ultra-low permeation also received much attention in the industries of pharmaceuticals, food, beverage packaging, and organic light-emitting display applications [2]. Besides these protective functions, the oxide thin-film materials and nanostructures are extraordinary multifunctional crystals with a huge range of emerging application domains, such as sensors, displays, light emitters, photovoltaics, spintronics, piezoelectric motors, biotechnology, capacitors, transparent electronics, and next-generation memories [3]. These become the original motivation for proposing this Special Issue-Functional Oxide-Based Thin-Film Materials.

The functional oxide crystal has several favorable properties, including good transparency, high conductivity, a wide bandgap, and strong luminescence. Thin-film oxide materials have been grown on various substrates by hydrothermal, sol-gel, chemical bath deposition, sputtering, atomic layer deposition, pulsed laser deposition, chemical vapor deposition (CVD), hot filament CVD, plasma-enhanced CVD, etc. A number of breakthroughs over the past few years have driven an exponential energy in the research activity of this field.

This Special Issue on Functional Oxide-Based Thin-Film Materials aims at gathering together some of the specialists working with device applications, to shed light on the properties and behavior of thin-film oxides. The papers cover many aspects of thin-film science and technology from thin film to nanostructure, from material properties to optoelectronic applications, thus reflecting the many interests of the community of scientists active in the field.

Gallium oxide, a wide bandgap material, has received much attention in several possible applications. In [4], Lin and co-workers report the porous GaN layers surrounding the mesa region were transformed into insulating $\mathrm{GaOx}$ layers in a reflector structure through a lateral photoelectrochemical (PEC) oxidation process. The electroluminescence emission intensity was localized at the central mesa region by forming the insulating $\mathrm{GaOx}$ layers in a reflector structure as a current confinement aperture structure. The PEC light-emitting device structure with a current-confined aperture surrounded by insulating $\mathrm{GaO}$ x layers has the potential for InGaN resonance cavity light source applications. In [5], Wuu and co-workers report the synthesis and characterization of gallium oxide $\left(\mathrm{Ga}_{2} \mathrm{O}_{3}\right)$ thin films fabricated on glass substrates using a combination of chemical bath deposition and a post-annealing process. The nanocrystalline $\alpha-\mathrm{Ga}_{2} \mathrm{O}_{3}$ films obtained from $\mathrm{GaOOH}$ after annealing showed the photodegraded $90 \%$ of the methylene blue in a solution irradiated under an ultraviolet lamp for $5 \mathrm{~h}$. These results suggest that $\alpha-\mathrm{Ga}_{2} \mathrm{O}_{3}$ thin films can be very useful alternatives for the photocatalytic degradation of dyes during wastewater treatment.

Zinc oxide $(\mathrm{ZnO})$ is a versatile and inexpensive semiconductor with a wide direct band gap that has applicability in several scientific and technological fields. In [6], Amakali and co-workers report the synthesis of $\mathrm{ZnO}$ thin films via two simple and low-cost synthesis routes, i.e., the molecular precursor 
method and the sol-gel method, which were deposited successfully on microscope glass substrates. In [7], Díaz-Becerril et al. have investigated the tantalum-doped $\mathrm{ZnO}$ structures synthesized on silicon substrates by using a hot filament chemical vapor deposition reactor. Green photoluminescence (PL) was observed by the naked eye when Ta-doped samples were illuminated by ultraviolet radiation and confirmed by photoluminescence spectra. The PL intensity on the Ta-doped $\mathrm{ZnO}$ increased from those undoped samples up to eight times and the resistivity and the sheet resistance also decrease when there is a greater amount of tantalum in the film.

An interesting investigation into the series of nanometer scale $(33-70 \mathrm{~nm}) \mathrm{HfO}_{2}$ thin films grown on Si substrates under different conditions by atomic vapor deposition (AVD) is reported by Feng et al. in [8]. The comprehensive studies demonstrate that appropriate substrate temperature and oxygen flow are essential to the structure, chemical composition, and optical constants from the surface and interface of the $\mathrm{HfO}_{2}$ films deposited by AVD. This work with integrated experiment measurements and analyses has enhanced our understanding of AVD-grown $\mathrm{HfO}_{2}$ advanced materials.

An entirely different perspective on thin film oxides is presented by Chang and Chan. In their paper, [9], they investigated the heavily doped wide band gap semiconductors like aluminum-doped zinc oxide (AZO) and tin-doped indium oxide (ITO) for low emissivity glass (low-e glass), which is often used in energy-saving buildings. The emissivity and average visible transmittance for $\mathrm{H}_{2} / \mathrm{N}_{2}=$ $100 / 100$ plasma annealed AZO/ITO were $0.07 \%$ and $80 \%$, respectively, lying in the range of commercially used low emissivity glass.

Supercapacitors, excellent energy storage devices, can effectively alleviate the current energy crisis. Based on their obvious advantages, such as simple design, high-power density, a long cycling lifetime, and a short charge/discharge rate, supercapacitors have attracted much research interest in recent years. Zheng and co-workers in [10] have synthesized a NiO@ZnO (NZO) hybrid with different reaction times by a green hydrothermal method. A highest energy density of $27.13 \mathrm{Wh} \mathrm{kg}^{-1}$ can be achieved at a power density of $321.42 \mathrm{~W} \mathrm{~kg}^{-1}$. These desirable electrochemical properties demonstrate that the NZO hybrid is a promising electrode material for a supercapacitor.

Finally, we also presented a contribution concerned with a review article, using 1D zinc oxide $(\mathrm{ZnO})$ as a representative nanomaterial [11]. This article reviews the fabrication methods of $1 \mathrm{D} \mathrm{ZnO}$ nanostructures-including chemical vapor deposition, hydrothermal reaction, and electrochemical deposition - and the influence of the growth parameters on the growth rate and morphology. Important applications of $1 \mathrm{D} \mathrm{ZnO}$ nanostructures in optoelectronic devices are described. Several approaches to improve the performance of $1 \mathrm{D} \mathrm{ZnO-based} \mathrm{devices,} \mathrm{including} \mathrm{surface} \mathrm{passivation,} \mathrm{localized} \mathrm{surface}$ plasmons, and the piezo-phototronic effect, are summarized.

To conclude, I believe that this Special Issue on Functional Oxide-Based Thin-Film Materials touches on the latest advancements in several aspects related to material science: the synthesis of novel oxide, photoluminescence characteristics, photocatalytic ability, energy storage, light emitter studies, low emissivity glass coatings, and investigations of both nanostructure and thin film properties. I wish to express my deepest and sincere gratitude to all authors who contributed, for having submitted manuscripts of such excellent quality. I also wish to thank the Editorial Office of Crystals for the fast and professional handling of the manuscripts during the whole submission process and for the help provided.

Conflicts of Interest: The authors declare no conflict of interest 


\section{References}

1. Lin, T.-K.; Wang, W.-K.; Huang, S.-Y.; Tasi, C.-T.; Wuu, D.-S. Comparison of Erosion Behavior and Particle Contamination in Mass-Production CF4/O2 Plasma Chambers Using Y2O3 and YF3 Protective Coatings. Nanomaterials 2017, 7, 183. [CrossRef] [PubMed]

2. Hsu, C.-H.; Lin, Y.-S.; Wu, H.-Y.; Zhang, X.-Y.; Wu, W.-Y.; Lien, S.-Y.; Wuu, D.-S.; Jiang, Y.-L. Deposition of Silicon-Based Stacked Layers for Flexible Encapsulation of Organic Light Emitting Diodes. Nanomaterials 2019, 9, 1053. [CrossRef] [PubMed]

3. Peng, W.-C.; Chen, Y.-C.; He, J.-L.; Ou, S.-L.; Horng, R.-H.; Wuu, D.-S. Tunability of p- and n-channel TiOx Thin Film Transistors. Sci. Rep. 2018, 8, 9255. [CrossRef] [PubMed]

4. Chen, Y.-Y.; Jhang, Y.-C.; Wu, C.-J.; Chen, H.; Lin, Y.-S.; Lin, C.-F. Fabrication of GaOx Confinement Structure for InGaN Light Emitter Applications. Crystals 2018, 8, 418. [CrossRef]

5. Yeh, C.-Y.; Zhao, Y.-M.; Li, H.; Yu, F.-P.; Zhang, S.; Wuu, D.-S. Growth and Photocatalytic Properties of Gallium Oxide Films Using Chemical Bath Deposition. Crystals 2019, 9, 564. [CrossRef]

6. Amakali, T.; Daniel, L.S.; Uahengo, V.; Dzade, N.Y.; Leeuw, N.H. Structural and Optical Properties of ZnO Thin Films Prepared by Molecular Precursor and Sol-Gel Methods. Crystals 2020, 10, 132. [CrossRef]

7. Herrera, V.; Díaz-Becerril, T.; Reyes-Cervantes, E.; García-Salgado, G.; Galeazzi, R.; Morales, C.; Rosendo, R.; Nieto-Caballero, F.G. Highly Visible Photoluminescence from Ta-Doped Structures of ZnO Films Grown by HFCVD. Crystals 2018, 8, 395. [CrossRef]

8. Luo, X.; Li, Y.; Yang, H.; Liang, Y.; He, K.; Sun, W.; Lin, H.-H.; Yao, S.; Lu, X.; Wan, L.; et al. Investigation of HfO2 Thin Films on Si by X-ray Photoelectron Spectroscopy, Rutherford Backscattering, Grazing Incidence X-ray Diffraction and Variable Angle Spectroscopic Ellipsometry. Crystals 2018, 8, 248. [CrossRef]

9. Chang, S.-C.; Chan, H.-T. Effect of Nitrogen Flow in Hydrogen/Nitrogen Plasma Annealing on Aluminum-Doped Zinc Oxide/Tin-Doped Indium Oxide Bilayer Films Applied in Low Emissivity Glass. Crystals 2019, 9, 310. [CrossRef]

10. Zheng, J.; Zhang, R.; Cheng, K.; Xu, Z.; Yu, P.; Wang, X.; Niu, S. Research on the High-Performance Electrochemical Energy Storage of a NiO@ZnO (NZO) Hybrid Based on Growth Time. Crystals 2019, 9, 47. [CrossRef]

11. Ding, M.; Guo, Z.; Zhou, L.; Fang, X.; Zhang, L.; Zeng, L.; Xie, L.; Zhao, H. One-Dimensional Zinc Oxide Nanomaterials for Application in High-Performance Advanced Optoelectronic Devices. Crystals 2018, 8, 223. [CrossRef]

(C) 2020 by the author. Licensee MDPI, Basel, Switzerland. This article is an open access article distributed under the terms and conditions of the Creative Commons Attribution (CC BY) license (http://creativecommons.org/licenses/by/4.0/). 